eCommons@AKU

April 2016

\title{
Paucity of trauma literature from a highly burdened developing country
}

Rizwan Sultan

Aga Khan University, Rizwan.sultan@aku.edu

Hasnain Zafar

Aga Khan University, hasnain.zafar@aku.edu

Follow this and additional works at: http://ecommons.aku.edu/pakistan_fhs_mc_surg_surg Part of the Surgery Commons

\section{Recommended Citation}

Sultan, R., Zafar, H. (2016). Paucity of trauma literature from a highly burdened developing country. Trauma, 18(2), 129-133.

Available at: http://ecommons.aku.edu/pakistan_fhs_mc_surg_surg/494 


\title{
Paucity of trauma literature from a highly burdened developing country
}

Trauma

2016, Vol. 18(2) 129-133

(C) The Author(s) 2015

Reprints and permissions: sagepub.co.uk/journalsPermissions.nav DOI: 10.1 | 77//4604086/56/9435 tra.sagepub.com

SAGE

\author{
Rizwan Sultan and Hasnian Zafar
}

\begin{abstract}
Introduction: Trauma is the leading cause of death among a younger population not only in USA but in Pakistan as well. The high prevalence of disease should result in a larger amount of data and a larger number of publications resulting in the ability to explore improvements in the field. This study aimed to review the trauma literature generated from Pakistan.

Methods: Journals indexed with PubMed from January 2010 to December 2014 were searched using the search term "Trauma AND Pakistan" filtering for relevant dates and human reports only. The abstracts and articles were reviewed by the authors to collect data on a proforma.

Results: I 4 articles were published from Pakistan during these five years; $64 \%$ of articles were published in international journals; $63 \%$ of articles were published in journals with an Impact Factor less than I; 54\% of articles were published from one of four provinces of Pakistan; 64\% of articles provided Level 4 evidence whilst another I4\% of articles provided Level 5 evidence on the topic; $55 \%$ of articles discussed epidemiology in non-representative populations.

Conclusions: Trauma literature from Pakistan is not only lacking significantly in quantity but is also of poor quality and is unable to offer conclusions on a particular trauma subject. There is huge room for improvement in the upcoming years.
\end{abstract}

\section{Keywords}

Trauma, literature, level of evidence, Pakistan

\section{Introduction}

According to the US Center for Disease Control (CDC) statistics for 2014, trauma is the leading cause of death of Americans aged $1-46$ years and is the third commonest cause of death overall. ${ }^{1}$ It accounts for 41 million Emergency Room (ER) visits in the USA each year and about 2 million hospital admissions costing more than $\$ 585$ billion. $^{2}$ Furthermore, in America more than 192,000 die from trauma annually ${ }^{2}$ and it accounts for $30 \%$ of life years lost, which is equal to the combined life years lost from all cancers, heart diseases, and HIV. ${ }^{3}$

Such statistics are of limited value in developing countries. Many sick or injured people in these countries never receive medical care from orthodox health facilities, and many deaths are not reported, making health records an incomplete source of data. ${ }^{4}$ Injury as a research problem has also been largely ignored in developing countries; ${ }^{5-7}$ yet, according to some data, Pakistan, a developing country with a population approximately half of that of the USA (180.44 million in 2013), sustains more than 2 million accidents each year, and road traffic accident rates have increased 17 times over the last 30 years. ${ }^{8}$ More than 50,000 people die every year and more than $>500,000$ are injured from trauma in Pakistan. ${ }^{9}$ According to a report by the World Health Organization (WHO), the actual number of road deaths in Pakistan is probably more than six times the actual reported number. ${ }^{10}$ People injured by terrorism also make a large component of trauma victims in Pakistan; there were six reported terrorist incidents in USA in $2013^{11}$ compared to at least 74 incidents in Pakistan ${ }^{12}$ which expends a lot of resources in a health care system.

Unlike the USA, there are no designated trauma centers in Pakistan.There are 94 teaching institutes

Department of Surgery, Aga Khan University Hospital Karachi, Pakistan Corresponding author:

Rizwan Sultan, Department of Surgery, Aga Khan University Hospital, Karachi 74800, Pakistan.

Email: rizwan.sultan@aku.edu 
providing tertiary care in Pakistan with $48(51 \%)$ in Punjab and $23(24.6 \%)$ in Sindh provinces; 55/94 $(58 \%)$ are private. The trauma burden is mainly carried by District headquarters hospitals and Government teaching hospitals in the bigger cities, as less than $1 \%$ of trauma presents to the private hospitals.

Evidence-based practice in medicine is becoming the standard of care, and it is recommended that evidencebased medicine is incorporated into clinical practice to improve patient outcome. ${ }^{13}$ In some diseases, there are well-recognized regional differences in behavior and outcome; in esophageal carcinoma for example, the spectrum of disease and outcome is totally different in the Japanese population compared to the rest of the world. Regional research in trauma is important because of differences in the quality of roads and vehicles used, mechanisms of injury and differences in prehospital and hospital care in different regions of the world result in a different spectrum of disease and outcomes. The diseases with greater prevalence in a geographical area are likely to be studied more, not only because of large numbers of patients, but also due to queries arising in the minds of clinicians while treating these patients. Unfortunately, like other fields of medicine, trauma is neglected by the researchers in developing countries.

This study reviews the trauma literature published from Pakistan in indexed journals over the last five years, the aspects of trauma covered in these articles, the quality of evidence contributed and the institutes which have published them.

\section{Material and methods}

All types of articles covering any aspect of trauma in the population of Pakistan published in a journal indexed on Pubmed between January 2010 and December 2014 were included. A PubMed search was conducted with the search term "Trauma AND Pakistan" filtered for the relevant dates of publication and restricted to human species reports only. All abstracts were read by the primary investigator to exclude irrelevant or duplicate articles.

All included articles were reviewed by both investigators and data were extracted on a bespoke data collection proforma capturing the title of the article, the name of the journal, year published, and impact factor (IF) of the journal (for the year in which the article was published according to www.researchgate.net). Also collected were the specialty institute and city of the corresponding author, study design, data collection tool, topic covered in the article, and level of evidence provided by the article. ${ }^{14}$ Data were analyzed using SPSS 19. Categorical data were expressed in percentages and proportions.

\section{Results}

A total of 333 abstracts were retrieved and filtering of these to exclude irrelevant articles reduced the number of included studies to 114 published over the five-year period in indexed journals from all over Pakistan (Table 1). Just over one-third (36\%) of articles were published in three National journals (Journal of Pakistan Medical Association, Journal of College of Physicians and Surgeons Pakistan, and Journal of Ayub Medical College); $35 \%$ of articles were published in journals with no IF and a further $28 \%$ in journals with an IF less than 1 . The government and semigovernment hospitals, which manage more than $95 \%$ of the trauma contributed only $49 \%$ of the trauma articles with over half $(54 \%)$ of all articles originating from a single, but second largest, province of Pakistan and virtually all of those (95\%) from a single city of that province (Figure 1). The articles were mainly case series and cross-sectional studies, reporting only the incidence and prevalence of trauma findings in non-representative samples. Three quarters $(78 \%)$ of articles provided no more than Level 4 or 5 evidence; only single articles provided Level $1^{15}$ or Level $2^{16}$ evidence. Details of the aspects of trauma reported in the 114 articles are shown in Figure 2, with $55.3 \%$ articles describing epidemiology in nonrepresentative samples - 14 articles covered different aspects of the $2005 \mathrm{Kashmir}$ earthquake, 16 articles were concerned with Road Traffic Accidents, 12 about traumatic brain injury, 9 reported bomb blast injuries and 9 discussed gunshot injuries. There were only five articles about different visceral injuries.

\section{Discussion}

The impact of trauma is greater than any other diseases in Pakistan, but the literature being produced in the country is sparse and provides a poor level of evidence. What little trauma literature is being generated comes from selected areas and is not generally representative of the whole population; similarly, the ratio of trauma literature generated by those Government hospitals which manage the vast majority of the trauma is much less than expected. Low-quality literature is being published in journals with low or absent IF, and while it is accepted that IF is not the sole measure of journal quality or importance, publishing in high IF journals will help to spread the message better about improving trauma care. The sparse nature of the content and low quality mean that it is not possible to draw any valid conclusions on the basis of local literature in order to make amendments in national trauma systems to improve the quality of trauma care thoughout the country of Pakistan. 
Table I. Characteristics of articles.

\begin{tabular}{|c|c|c|c|}
\hline Variable & Frequency (\%) & Variable & Frequency (\%) \\
\hline \multicolumn{2}{|l|}{ Year of publication } & \multicolumn{2}{|l|}{ Province of corresponding author } \\
\hline 2010 & $25(21.9)$ & Sindh & $62(54.4)$ \\
\hline 2011 & $20(17.5)$ & Karachi & $59(95.2)$ \\
\hline 2012 & $22(19.3)$ & Punjab & $17(14.9)$ \\
\hline 2013 & $32(28.1)$ & Khyber PakhtunKhwa & $13(11.4)$ \\
\hline \multirow[t]{2}{*}{2014} & $15(13.2)$ & Islamabad & II (9.6) \\
\hline & & Baluchistan & 0 \\
\hline \multicolumn{2}{|l|}{ Status of journal } & \multicolumn{2}{|l|}{ Study design } \\
\hline National & $4 I$ (35.9) & Meta-analysis & I $(0.9)$ \\
\hline \multirow[t]{6}{*}{ International } & $73(64.1)$ & Cohort & $2(1.8)$ \\
\hline & & Case control & $2(1.8)$ \\
\hline & & Cross-sectional studies & $28(24.6)$ \\
\hline & & Case series & $65(57)$ \\
\hline & & Case reports & $8(7)$ \\
\hline & & Commentary/expert opinions/letter to editor & $8(7)$ \\
\hline \multicolumn{2}{|l|}{ Impact factor } & \multicolumn{2}{|l|}{ Level of evidence } \\
\hline Not Allocated & $40(35.1)$ & 1 & I (I.9) \\
\hline $0.1-1.00$ & $32(28.1)$ & 2 & I $(0.9)$ \\
\hline $1.1-2.00$ & $28(24.6)$ & 3 & $23(20.2)$ \\
\hline $2.1-3.00$ & II (9.6) & 4 & $73(64)$ \\
\hline $3.1-4.00$ & $2(1.8)$ & 5 & $16(14)$ \\
\hline$>4.0$ & I (0.9) & & \\
\hline \multicolumn{2}{|c|}{ Institutions of corresponding author } & \multicolumn{2}{|l|}{ CEBM categories } \\
\hline Government/semi-government & $56(49.1)$ & Epidemiology & $63(55.3)$ \\
\hline Private & $46(40.3)$ & Diagnosis & 16 14) \\
\hline WHO & $4(3.5)$ & Treatment benefits/harms & $35(30.7)$ \\
\hline Foreign & $8(7.0)$ & Screening & $0(0)$ \\
\hline \multicolumn{4}{|l|}{ Specialty of author } \\
\hline General surgery & $2 \mid(18.4)$ & & \\
\hline Neurosurgery & $18(15.8)$ & & \\
\hline Emergency medicine & $13(1 \mathrm{l} .4)$ & & \\
\hline Orthopedics & $12(10.5)$ & & \\
\hline Plastics & $8(7.0)$ & & \\
\hline${ }^{\mathrm{a}}$ Others & $42(36.8)$ & & \\
\hline
\end{tabular}

WHO: world health organization; CEBM: Centre for Evidence Based Medicine.

${ }^{a}$ Others include community medicine, forensic medicine, cardiothoracic surgery, psychiatry, rehabiliation.

Baluchistan is the largest province of Pakistan by area but has contributed no data at all to the trauma literature during these five years, whereas Punjab, which is the largest province by population has contributed only $15 \%$ of the data. Sindh, has contributed $54 \%$ of the trauma literature but nearly all of it $(95 \%)$ originates from a single city of this province - in other words, the single city of Karachi with an estimated population of 23.4 million in $2013,{ }^{17}$ has contributed more than half of all of Pakistan's trauma literature over a five-year period, which should alarm both the Government authorities and the health care personnel of Pakistan.

It is clear from Figure 2 that many vital aspects of trauma care have been ignored throughout the country as there is no little or no literature produced on important issues such as pre-hospital trauma treatment, emergency management including blood transfusions and resuscitation, damage control surgery, trauma teams, 


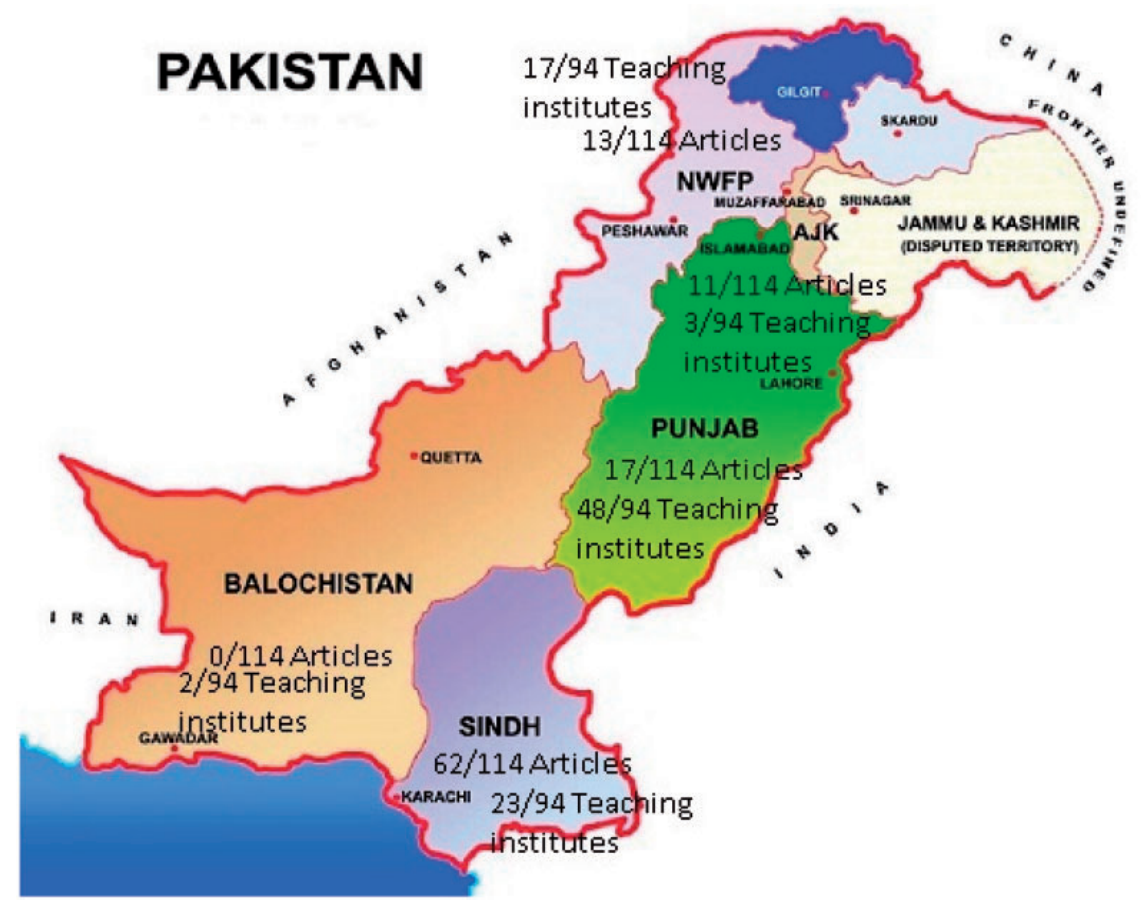

Figure I. Trauma articles and institutes per province. The rest of the articles are by foreign authors (eight who participated in the 2005 Kashmir earthquake effort and three studies from members of the World Health Organization).

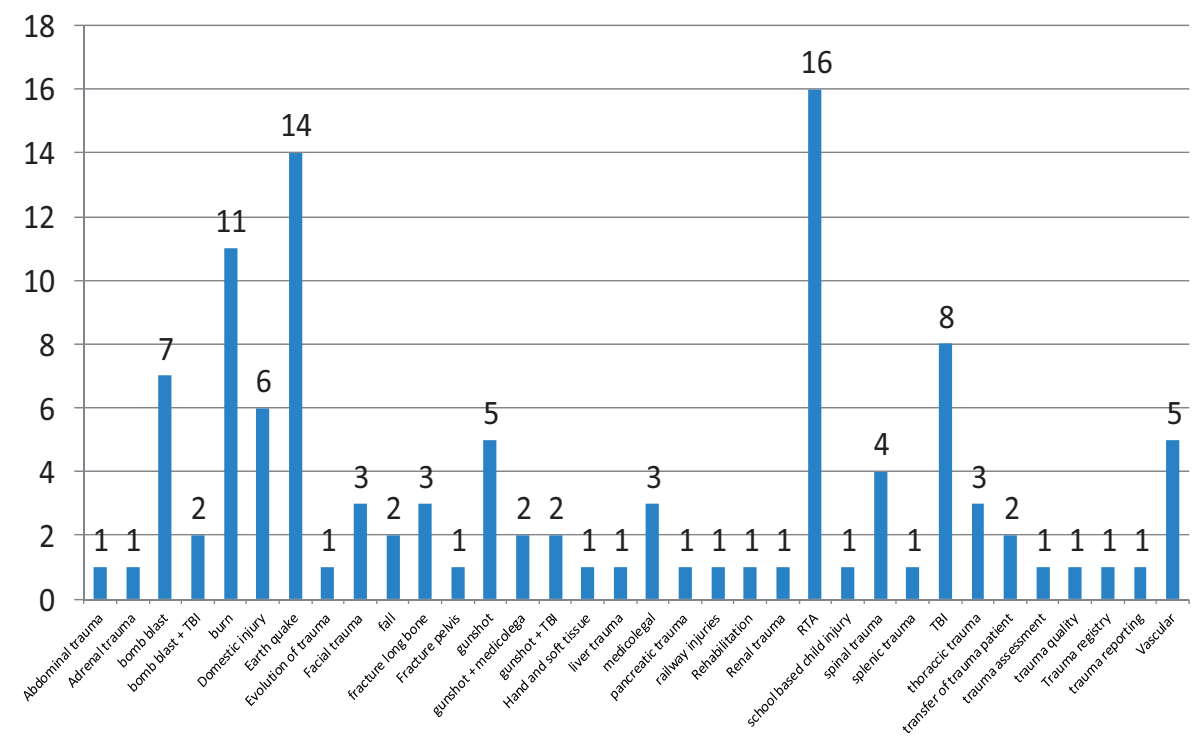

Figure 2. Articles grouped on the basis of aspect covered.

comparison of different interventions, and rehabilitation of trauma patients.

The lack of ability to produce good literature is multifactorial and includes the lack of availability of national registry programs, the absence of designated trauma centers across the country, untrained staff collecting prospective data, poorly trained people analyzing the data, and poor writing skills. In addition, it is recognsied that many healthcare professional's motivation for writing is to achieve a promotion rather than to produce high-quality literature which might improve the trauma systems countrywide.

There are a variety of relatively simple measures that can improve the quality of research, such as increasing 
awareness at the national level, as well as at the level of each hospital, regarding the importance of regional trauma research and its implications. The public of Pakistan need to be educated to inform the relevant authorities about each trauma incident and each mortality should be registered in newly established national or local trauma registries. A pre-hospital care system should be established and staff properly trained about the safe and immediate transfer of unstable trauma patients to regional centers and collaborative research between the institutions of a single city and with other cities is required to compare differences in trauma care and outcome to provide the evidence to drive improvement across the country. Referrals from one center to another should also be properly documented and communicated to the referred hospital trauma team. There is an overwhelming need for epidemiological workshops and courses to make medical staff able to plan better studies, collect better data, interpret it correctly, and get it published in well-reputed journals; similarly, there are a wide range of areas still to be explored including different interventions in trauma. These steps are essential to provide better trauma care to the people of Pakistan.

\section{Conclusion}

Trauma literature from Pakistan, an overburdened developing country, is scanty and provides a low level of evidence. The generation of trauma literature is not uniform across the country leaving significant room for improvement. The relevant national authorities should take steps to ensure quality research is produced to improve the outcomes of trauma in Pakistan.

\section{Authors' contributions}

Rizwan Sultan: literature search, study design, data collection, data analysis, data interpretation, writing, critical revision.

Hasnain Zafar: concept of study, data collection, data analysis, data interpretation, writing, critical revision.

\section{Declaration of conflicting interests}

The author(s) declared no potential conflicts of interest with respect to the research, authorship, and/or publication of this article.

\section{Funding}

The author(s) received no financial support for the research, authorship, and/or publication of this article.

\section{Provenance and peer review}

Not commissioned, externally peer reviewed.

\section{References}

1. Rhee P, Joseph B, Pandit V, et al. Increasing trauma deaths in the United States. Ann Surg 2014; 260: 13-21.

2. Centers for Disease Control and Prevention, National Center for Injury Prevention and Control. Web-based injury statistics query and reporting system (WISQARS) 2015, www.cdc.gov/injury/wisqars (accessed 1 July 2015).

3. Trauma Statistics. www.nationaltraumainstitute.org/ home/trauma_statistics.html (accessed 11 August 2015).

4. Swarnkar M, Singh PK and Dwivedi S. Pattern of trauma in central India: an epidemiological study with special reference to mode of injury. Int $J$ Epidemiol 9.

5. Tursz A. Epidemiological studies of accident morbidity in children and young people: problems of methodology. World Health Stat Q 1985; 39: 257-267.

6. Zwi AB, Forjuoh S, Murugusampillay S, et al. Injuries in developing countries: policy response needed now. Trans R Soc Trop Med Hyg 1996; 90: 593-595.

7. Krug EG, Sharma GK and Lozano R. The global burden of injuries. Am J Public Health 2000; 90: 523.

8. Ahmed A. Road safety in Pakistan. Islamabad: National Road Safety Secretariat, Ministry of Communications, Government of Pakistan, 2007.

9. Trauma Care Initiative www.appna.org/index.php? option $=$ com_content $\&$ view $=$ article $\&$ id $=264 \&$ Itemid $=49$ (accessed 31 October 2015).

10. World Health Organization. Global status report on road safety: time for action. Geneva: World Health Organization, 2009.

11. Terrorist incidents in the United States in 2013. https:// en.wikipedia.org/wiki/Category:Terrorist_incidents_in_ the_United_States_in_2013 (accessed 11 A August 2015).

12. Terrorist incidents in Pakistan in 2013. http://en.wikipedia.org/wiki/Terrorist_incidents_in_Pakistan_in_2013 (accessed 6 June 2015).

13. Shortell SM, Rundall TG and Hsu J. Improving patient care by linking evidence-based medicine and evidencebased management. JAMA 2007; 298: 673-676.

14. OCEBM Levels of Evidence Working Group, "The Oxford Levels of Evidence 2", www.cebm.net/wp-con tent/uploads/2014/06/CEBM-Levels-of-Evidence-2.1.pdf (accessed 22 August 2015).

15. Razzak JA, Khan UR, Zia N, et al. A child an hour: burden of injury deaths among children under 5 in Pakistan. Arch Dis Child 98: 867-871.

16. Zafar SN, Khan AA, Ghauri AA, et al. Phenytoin versus leviteracetam for seizure prophylaxis after brain injury a meta analysis. BMC Neurol 2012; 12: 30.

17. Population explosion: Put an embargo on industrialization in Karachi, http://tribune.com.pk/story/614409/ population-explosion-put-an-embargo-on-industrialisa tion-in-karachi/ (accessed 31 October 2015). 
Copyright of Trauma is the property of Sage Publications, Ltd. and its content may not be copied or emailed to multiple sites or posted to a listserv without the copyright holder's express written permission. However, users may print, download, or email articles for individual use. 